\title{
Tangible pictures: Viewpoint effects and linear perspective in visually impaired people
}

\author{
Morton A Heller, Deneen D Brackett, Eric Scroggs, Heather Steffen, Kim Heatherly, \\ Shana Salik \\ Psychology Department, Physical Sciences Building, Eastern Illinois University, 600 Lincoln Avenue, \\ Charleston, IL 61920, USA; e-mail: cfmah1@eiu.edu \\ Received 16 July 2001, in revised form 11 January 2002
}

\begin{abstract}
Perception of raised-line pictures in blindfolded-sighted, congenitally blind, late-blind, and low-vision subjects was studied in a series of experiments. The major aim of the study was to examine the value of perspective drawings for haptic pictures and visually impaired individuals. In experiment 1 , subjects felt two wooden boards joined at $45^{\circ}, 90^{\circ}$, or $135^{\circ}$, and were instructed to pick the correct perspective drawing from among four choices. The first experiment on perspective found a significant effect of visual status, with much higher performance by the low-vision subjects. Mean performance for the congenitally blind subjects was not significantly different from that of the late-blind and blindfolded-sighted subjects. In a further experiment, blindfolded subjects drew tangible pictures of three-dimensional (3-D) geometric solids, and then engaged in a matching task. Counter to expectations, performance was not impaired for the 3-D drawings as compared with the frontal viewpoints. Subjects were also especially fast and more accurate when matching top views. Experiment 5 showed that top views were easiest for all of the visually impaired subjects, including those who were congenitally blind. Experiment 5 yielded higher performance for 3-D than frontal viewpoints. The results of all of the experiments were consistent with the idea that visual experience is not necessary for understanding perspective drawings of geometrical objects.
\end{abstract}

\section{Introduction}

The purpose of this study was to examine picture perception and linear perspective in people who are blind and those with low vision. Thus, perspective drawings provide very useful depth information for vision, but our aim here was to examine linear perspective and viewpoint effects in haptics. A further aim was to identify possible causes for difficulty in the perception of raised-line pictures that depict depth relations. We know that the viewpoint of a picture can matter in vision, and it is plausible to expect that some tangible pictures may vary in their utility as a function of viewpoint.

There has been relatively little research on depth perception in haptic displays (see Holmes et al 1998), and even less on linear perspective in haptics and the blind. Several studies in this area are noteworthy. Holmes et al (1998) recently presented texture gradients to early-blind and to sighted subjects. The subjects were asked to set a board to the appropriate slant after being given texture-gradient depictions that specified depth. They found that the early-blind subjects were able to perform as well as the sighted when asked to interpret these texture gradients. Arditi et al (1988) questioned whether blind people imagine the world using linear perspective, or even understand what that means. They asked blind people to imagine familiar objects of different sizes at a near and a far distance. The subjects were then asked to point to the sides of these imagined objects. According to Arditi et al, the congenitally blind subjects failed to show an understanding that image size decreases with distance.

Recently, Kennedy has provided a relatively optimistic appraisal of the value of tangible pictures for blind people (Kennedy 1993, 1997; also see Heller et al 1996a). According to Kennedy, outlines can be felt, just as they can be seen. Outlines represent surface edges for touch, on this view, and blind people are able to understand linear 
perspective, covering, and figure-ground relations (Kennedy 2000). There is little doubt that blind people can understand the vantage point taken in a drawing of a complex scene (Heller and Kennedy 1990; Heller et al 1995). Kennedy (1993) has also argued that blind children and adults understand perspective, since perspective basically involves understanding directions. Thus, blind people were asked to point to the tops of buildings from near and from far. They indicated a more acute angle when pointing from afar (Kennedy 1993, page 197). However, there is a considerable difference between pointing, knowing that other vantage points exist (and adopting those vantage points), and understanding linear perspective in haptics or in drawings (Heller et al 1996b).

One might expect that linear perspective would not be accessible to haptics, since tangible rectangles show shape constancy when tilted. Squares and rectangles do not feel trapezoidal when at a slant, and this 'perspective distortion' may be limited to the experience of foreshortening and linear perspective that is found in sight. Heller et al (1996b) found that naïve, congenitally blind (CB) subjects did not spontaneously produce foreshortened tangible drawings when trying to draw slanted boards. Thus, their drawings were all the same height, despite slant in depth. CB people lack visual experience, and probably lack visual imagery. They also do not have much experience with pictures. It was therefore not surprising that they did not spontaneously generate foreshortened drawings, that is drawings that became progressively narrower when representing a board at a slant. However, CB subjects were able to correctly match up the appropriate foreshortened drawing with a slanted board after feeling the set of perspective drawings. They were also informed that the set of perspective drawings showed how a slanted board looked to a sighted person, but they were not given any feedback. This exposure to the range of drawings was sufficient to allow the CB subjects to solve the problems posed by drawings of objects in depth. These results suggest that $\mathrm{CB}$ people are likely to benefit from instruction in drawing.

However, CB subjects sometimes outperform blindfolded-sighted subjects in picture perception tasks that control for differential familiarity. Heller and Kennedy (1990) found that blind subjects performed better than sighted individuals at locating their drawings in a display. More recently, Heller et al (1996b) reported that CB subjects were superior to blindfolded-sighted subjects in selecting the correct perspective drawing of a vertical, rectangular panel.

Pictures have the potential of being extremely useful to visually impaired people, but far too little is known about factors that interfere with the interpretation of tangible pictures, and those that help. It is clear that some pictures are recognizable by touch (Heller et al 1996a), but others are more difficult to recognize (see Millar 2000). Some earlier researchers have assumed that pictures may have utility for touch and for blind people, but require practice and instruction (eg Merry and Merry 1933). According to Hatwell (1984), CB subjects do poorly on geometric tasks, but this is because they have had few opportunities to engage in drawing. Hatwell believes that this lack of experience derives from a limitation in technology.

Revesz (1950) argued that touch leads to an inadequate understanding of proportion or symmetry, and can only provide one with a very limited understanding of spatial relations. Revesz thought that two-dimensional (2-D) configurations have limited value for touch. This theoretical viewpoint may lead to a negative prognosis on the value of drawing for blind people, since drawings are 2-D displays. Moreover, if it is assumed that touch can not provide adequate information about spatial relations, one is then led to the belief that $\mathrm{CB}$ individuals will not find tangible pictures of much use. $\mathrm{CB}$ people are unlikely to be able to visualize patterns that they touch, and some researchers have assumed that this visualization process is essential for coding forms that are explored by touch (for a discussion of these issues, see Heller 1989a, 1991, 2000; Heller and Brabyn 1997; Heller et al 1996a, 2001; Lederman et al 1990; Millar 1991, 1994). 


\section{Viewpoint effects in haptics}

In addition to an examination of depth relations in pictures, the present research was designed to evaluate the effect of the point of view, or the vantage point of tangible drawings. The viewpoint of a picture is intimately related to linear-perspective information. In vision, we know that some objects are more readily recognized when seen from familiar viewpoints (see Farah 2000; Rock and DiVita 1987). Moreover, Newell et al (2001) reported that haptics "... recognize the objects best from the back". They claimed that, unlike vision, the hands preferred the back 'view' of objects. One may produce drawings of objects from a variety of viewpoints, such as top views, from the side, or front views, or from elevated, three-dimensional (3-D) views.

One complicating factor in this area is that there are some classes of pictures that may be a special problem for touch. Heller et al (1995) found that CB subjects, indeed all subjects, had difficulty with 3-D perspective drawings of a model house. They reported that subjects performed much better when examining side views. In much earlier research, Heller (1989a) found that many blind subjects spontaneously produced side views or frontal views when asked to make raised-line drawings of tables for the first time. While some subjects generated fold-out, elevated views (also see Kennedy 1993), bird's-eye views were much less common than side-view or frontal-view depictions of common objects. Consequently, the present experiments were designed to more fully explore the possible difficulties involved when blind people attempt to interpret drawings of 2-D and 3-D configurations, especially those involving linear perspective.

It was expected that subjects would have the most difficulty with haptic foreshortened 3-D drawings of geometric solids. Frontal views were expected to be relatively easy for the subjects. The lowest performance was initially predicted for top views, given the difficulty previously found with elevated views of model houses (Heller et al 1995). Of course, the difficulty with top views in Heller et al (1995) could have derived from the top viewpoint, or foreshortening, or a combination of the two factors. The two effects could be independent and additive. It should be noted that in some ways this prediction about 3-D views is counter-intuitive. Visually, 3-D perspective views provide the greatest amount of useful information about depth relations and form. However, the increased complexity of these arrays, and consequent information load could increase task difficulty for touch. CB people are unfamiliar with the conventions involved in perspective drawings, and this could increase task difficulty for them.

If visual experience or visual imagery were necessary for perception of perspective representations, one would expect poorer performance by CB subjects. None of the earlyblind subjects in these experiments had prior experience with perspective drawings. The second experiment reported here examined viewpoint effects in blindfoldedsighted subjects. An additional experiment compared CB, late-blind (LB), low-vision (LV), and blindfolded-sighted subjects in a task involving linear-perspective and viewpoint effects. If visual experience were necessary for the correct interpretation of perspective drawings, one would expect that $\mathrm{CB}$ participants would have special difficulty with foreshortened drawings involving converging lines and linear perspective, and any drawings that expressed depth relations.

\section{Experiment 1: Linear perspective}

The aim of this experiment was to study linear perspective in visually impaired people. One might expect that object edges would not converge in the distance for touch, nor should objects change their apparent shape as a function of orientation. Subjects in experiment 1 matched perspective drawings against solid objects derived from intersecting planes. 


\subsection{Method}

3.1.1 Participants. The visually impaired subjects were twenty-seven (twelve males, fifteen females) volunteers with various degrees of visual loss (see table 1). The nine CB subjects were blind from birth, or lost sight during the first year of life. The nine LB subjects lost sight after the first year of life. In addition, nine subjects with very low vision (LV) were included in the study. LV subjects were defined as those subjects with some light perception, perhaps some object perception, and, at most, very minimal pattern perception. The LV subjects had less than 'shadow vision' and many could not, for example, locate the direction of strong light sources.

About half of the visually impaired subjects participated in two of the experiments reported here, with a year between experiments 1 and 5. A blindfolded-sighted control group (three males, six females; age range $19-45$ years, $M=23.9$ years) was recruited on the campus of Eastern Illinois University for the first experiment.

3.1.2 Stimuli and apparatus. A Swedish raised-line drawing kit and a ballpoint pen were used to produce the stimuli for all of the experiments reported here (see figures 1 and 2). A durable thick raised line, both tangible and visible, was produced when the pen was drawn over the textured surface. Wooden stimuli were formed from two pieces of $8.6 \mathrm{~cm} \times 8.6 \mathrm{~cm}, 1.2 \mathrm{~cm}$ thick birch plywood (see figures $1 \mathrm{a}-1 \mathrm{c}$ ). The plywood pieces were joined together at three angles: $45^{\circ}$ (acute-angle stimulus), $90^{\circ}$ (right-angle stimulus), and $135^{\circ}$ (obtuse-angle stimulus). The back panels were vertical. Each stimulus was attached with an angle iron to a $42 \mathrm{~cm} \times 6 \mathrm{~cm}$ baseboard. The wooden stimuli were never oriented straight-ahead, but were always presented at $+45^{\circ}$, as in figures $2 \mathrm{a}-2 \mathrm{c}$, or at $-45^{\circ}$. Outlines of the baseboards were drawn on a $62 \mathrm{~cm} \times 81 \mathrm{~cm}$ piece of mat board, with the closest point at the subject's body midline. This was done to ensure that the stimuli were consistently placed at the appropriate orientations.

Raised-line drawings of the stimuli were made for the matching task (see figures $2 \mathrm{a}-2 \mathrm{c}$ for examples). The drawings depict the wooden objects with their two panels meeting at $45^{\circ}, 90^{\circ}$, and $135^{\circ}$ angles, assuming an eye-level vantage point. Thus, the raised-line drawings adopted a vantage point with the viewer's eye level with the top of the rear panel and at a viewing distance of approximately $50 \mathrm{~cm}$. Note that figure $2 \mathrm{a}$ is at $45^{\circ}$ left and figures $2 \mathrm{~b}$ and $2 \mathrm{c}$ are at $45^{\circ}$ right. The drawing of the acute stimulus included overlap of the planes (figure $2 b$ ).

Each set of choices for the matching task included the correct depiction of the object (acute angle, right angle, or obtuse angle), a drawing of the object oriented $90^{\circ}$ in the opposite direction (a mirror reflection), and two other randomly chosen pictures drawn from the set of pictures of the other objects. The choice pictures were placed parallel to the front edge of the table, and spaced approximately $3.5 \mathrm{~cm}$ to $6.5 \mathrm{~cm}$ from each other, with the middle of the horizontal array at the subjects' body midline. The wooden stimuli were placed behind the choices, at the appropriate orientation. This placement allowed the subject to simultaneously feel the object with one hand, and the choices with the other hand.

There were 2 random sequences of pictures with 6 trials in each sequence, for a total of 12 trials. Each stimulus object was presented once in the $-45^{\circ}$ orientation and once in the $+45^{\circ}$ orientation (with respect to the body midline, turned to the left or right) in each sequence. The order of presentation of the sequences was balanced, so that half of the subjects began with one sequence and half began with the other. A correct choice required that subjects discern the orientation of the stimulus and select the drawing with the appropriate amount of foreshortening and covering (or lack thereof). 
Table 1. Characteristics of the visually impaired subjects, including gender, age, education, age of onset, cause of blindness, and presence of light perception (LP).

Gender Age/years Education Age of onset Cause Light perception

\begin{tabular}{|c|c|c|c|c|c|}
\hline \multicolumn{6}{|c|}{ Congenitally blind $(\mathrm{CB})$} \\
\hline M & 46 & MA & 0 & ROP & yes \\
\hline $\mathrm{F}$ & 28 & HS & 0 & ROP & no \\
\hline $\mathrm{F}$ & 37 & $\mathrm{JD}$ & 0 & ROP & no \\
\hline $\mathrm{F}$ & 46 & HS & 0 & ROP & yes* \\
\hline $\mathrm{F}$ & 29 & SG & 0 & $\begin{array}{l}\mathrm{RP} \text {, nystagmus, and } \\
\text { other unknown causes }\end{array}$ & yes \\
\hline $\mathrm{F}$ & 53 & HS & 0 & $\begin{array}{l}\text { RP, nystagmus, and } \\
\text { other unknown causes }\end{array}$ & yes \\
\hline M & 53 & $\mathrm{SC}$ & 0 & unknown & yes* \\
\hline M & 47 & JD & 0 & ROP & no* \\
\hline M & 60 & SG & 0 & $\begin{array}{l}\text { congenital glaucoma, and } \\
\text { other unknown causes }\end{array}$ & no \\
\hline M & 46 & HS & 0 & ROP & no* \\
\hline M & 45 & GED & 0 & ROP & no \\
\hline $\mathrm{F}$ & 57 & HS & 0 & ROP & no \\
\hline $\mathrm{F}$ & 59 & $\mathrm{PhD}$ & 0 & ROP & no \\
\hline \multicolumn{6}{|c|}{ Late blind ( $L V)$} \\
\hline $\mathrm{F}$ & 57 & SG & 10 & RP & yes \\
\hline $\mathrm{F}$ & 34 & $\mathrm{SC}$ & 7 & detached retina & no* \\
\hline M & 54 & $\mathrm{PhD}$ & 42 & virus & no \\
\hline M & 65 & $\mathrm{PhD}$ & 29 & diabetes & yes* \\
\hline M & 31 & $\mathrm{SG}$ & 9 & optic nerve trauma & yes* \\
\hline M & 57 & MA & 2 & retinal blastoma & no \\
\hline M & 28 & $\mathrm{SC}$ & 17 & cataracts & no \\
\hline $\mathrm{F}$ & 58 & HS & 2 & spinal meningitis & yes* \\
\hline $\mathrm{M}$ & 56 & $\mathrm{BA}$ & 2 & retinal blastoma & no \\
\hline M & 51 & $\mathrm{JD}$ & 5 & cataracts/glaucoma & no* \\
\hline $\mathrm{F}$ & 25 & AS & 16 & virus & yes \\
\hline $\mathrm{F}$ & 46 & $\mathrm{BA}$ & 45 & ROP & no \\
\hline M & 47 & $\mathrm{BA}$ in $\mathrm{MS}$ & 33 & macular degeneration & no \\
\hline M & 57 & HS & 35 & glaucoma/detached retina & no \\
\hline M & 69 & BA & 65 & farm accident & no \\
\hline \multicolumn{6}{|c|}{ Low vision $(L V)$} \\
\hline $\mathrm{F}$ & 22 & $\mathrm{SC}$ & 0 & ROP & yes \\
\hline M & 24 & $\mathrm{BA}$ in $\mathrm{MA}$ & 13 & $\mathrm{RP}$ & yes \\
\hline $\mathrm{F}$ & 43 & $\mathrm{SC}$ & 23 & RP & yes \\
\hline $\mathrm{F}$ & 38 & MA & 36 & RP & yes \\
\hline M & 63 & HS & 0 & $\begin{array}{l}\text { congenital cataracts, } \\
\text { nystagmus; LV in one eye }\end{array}$ & yes* \\
\hline $\mathrm{F}$ & 41 & SG & 15 & diabetic retinopathy & yes (one eye)* \\
\hline $\mathrm{F}$ & 69 & GED & 20 & macular degeneration & yes \\
\hline M & 30 & $\mathrm{SC}$ & 8 & hydrocephalus & yes \\
\hline $\mathrm{F}$ & 52 & HS & 0 & ROP, detached retina & yes \\
\hline $\mathrm{F}$ & 25 & $\mathrm{SC}$ & 0 & $\begin{array}{l}\text { iritis, glaucoma, } \\
\text { detached retina }\end{array}$ & yes (one eye)* \\
\hline $\mathrm{F}$ & 23 & SG & 23 & blood clots in brain & yes \\
\hline M & 47 & MA & unknown & RP & yes \\
\hline M & 47 & AS & 8 & RP & yes \\
\hline
\end{tabular}

Note: F, female; M, male; LV, low vision; ROP, retinopathy of prematurity; RP, retinitis pigmentosa; SC, some college; SG, some graduate school; AS, junior college degree; BA, college degree; MA, Master of Arts degree; GED, high school equivalency diploma; HS, high school diploma; PhD, Doctor of Philosophy degree; JD, law degree. Congenitally blind (CB) subjects with light perception lack visual form perception, and are unable to see close hand motion.

* Indicates a subject new to the haptic viewpoint task of experiment 5. 

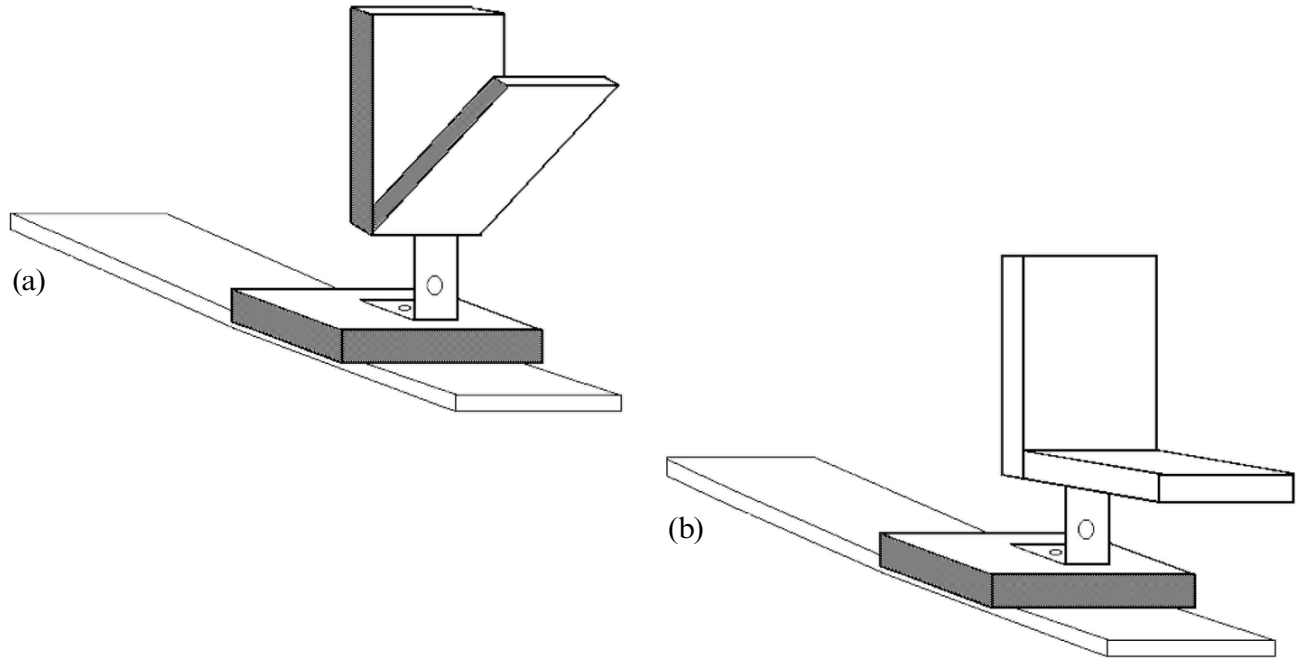

(c)

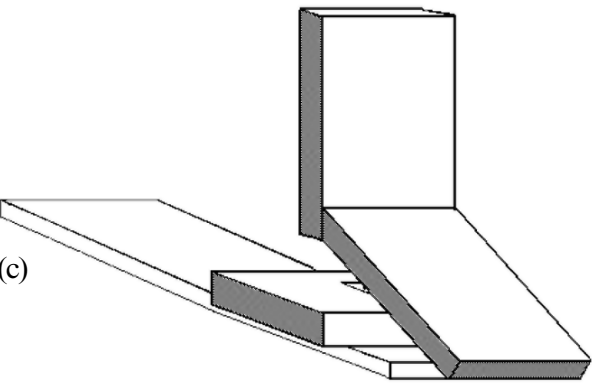

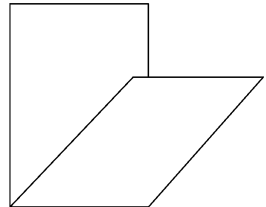

(b)

Figure 1. (a) Acute-angle stimulus object with planes intersecting at $45^{\circ}$ angle. Note that all of the stimuli in figure 1 are oriented at $+45^{\circ}$ from the vantage point of the subject, ie to the subject's right; (b) right-angle stimulus object with planes intersecting at $90^{\circ}$; (c) obtuse-angle stimulus object with planes intersecting at $135^{\circ}$.

(a)

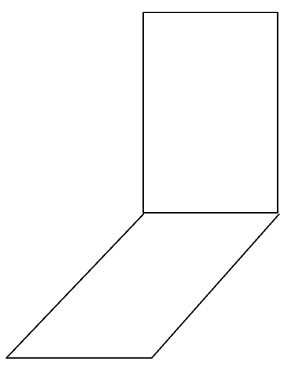

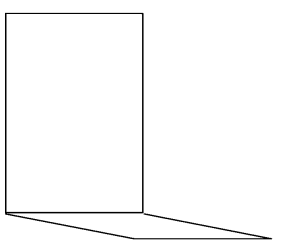

(c)

Figure 2. (a) Drawing of obtuse-angle stimulus object oriented at $-45^{\circ}$ from the vantage point of the subject; (b) drawing of acuteangle stimulus object oriented at $+45^{\circ}$; (c) drawing of right-angle stimulus object oriented at $+45^{\circ}$.

3.1.3 Design and procedure. The experiment was a between - within ANOVA, with visual status as the between-groups variable, with repeated measures on stimulus object (acute angle, right angle, obtuse angle). The subjects were told that they would feel wooden objects in different orientations and then draw pictures of the objects using a raised-line drawing kit. They were instructed to imagine how the objects would appear 
with their tops at eye level (that is, looking across their tops) and to draw them from that vantage point. The experimenter guided the subjects' hands to demonstrate the vantage point. Both blindfolded and visually impaired subjects drew six pictures on raised-line drawing paper, one picture of each of the three objects (acute angle, right angle, obtuse angle) in the left and right orientation. Subjects were not given feedback on their performance in any of the experiments reported here.

In the next phase of the experiment, subjects felt the objects, that is the stimuli with panels at different angles, and the raised-line choices. The visually impaired subjects were told that the drawings showed how the objects appeared to sighted people, from the vantage point of looking across the tops of the back panel. They were told to find the correct drawing from among the four choices and indicate their choice by tapping the picture. Subjects could feel both the object and the raised-line pictures using free exploration in any manner that they chose. They were permitted to repeatedly feel the stimulus object as they explored the picture choices, and were told to feel all of the choices before making a match.

\subsection{Results and discussion}

Table 2 shows a summary of the results of the experiment, with superior performance by the LV subjects. A 4 (visual status) $\times 3$ (object) ANOVA conducted on number correct yielded significant main effects of visual status $\left(F_{3,32}=5.88, p<0.01\right)$ and stimulus object $\left(F_{2,64}=17.88, p<0.001\right)$. The interaction between visual status and stimulus object was not significant $(F<1)$. With the data collapsed over stimulus object, the mean numbers correct for the $\mathrm{CB}, \mathrm{LB}, \mathrm{LV}$, and sighted subjects were 6.3, 8.4, 10.4, and 7.9, respectively. A Newman-Keuls test performed on these means revealed that LV subjects scored significantly higher than the $\mathrm{CB}$ and blindfolded-sighted subjects $(p<0.01)$, but the differences between the means for the CB, LB, and blindfoldedsighted subjects were not significant $(p>0.05)$, as was the comparison between the LV and LB subjects $(p>0.05)$. Blindfolded-sighted subjects performed similarly in accuracy to the LB subjects.

Table 2. Mean number correct (with standard deviations in parentheses) in perspective task for visually impaired and blindfolded-sighted subjects in experiment 1.

\begin{tabular}{llllr}
\hline Subjects & \multicolumn{4}{l}{ Angle of stimulus object/ } \\
\cline { 2 - 5 } & 45 & 90 & \multicolumn{1}{c}{135} & \multicolumn{1}{c}{ overall } \\
\hline Congenitally blind (CB) & $2.3(1.1)$ & $1.2(1.3)$ & $2.8(1.4)$ & $6.3(2.7)$ \\
Late blind (LB) & $3.2(0.8)$ & $1.8(1.7)$ & $3.4(1.0)$ & $8.4(2.1)$ \\
Low vision (LV) & $4.0(0.0)$ & $2.6(1.6)$ & $3.9(0.3)$ & $10.4(1.7)$ \\
Sighted & $2.9(1.2)$ & $1.8(1.1)$ & $3.2(1.3)$ & $7.9(1.5)$
\end{tabular}

Note: The maximum number of correct judgments per object angle $=4$; maximum total number correct $=12$.

Mean performance (out of a possible score of 4) was lower for the right-angle object ( $M=1.8$ correct) than for the acute-angle object $(M=3.1$ correct) or the obtuse-angle object ( $M=3.3$ correct). A Newman-Keuls test on these means showed that performance on the right-angle stimulus was significantly lower than that for both of the other stimuli $(p<0.01)$. The means for the acute-angle and obtuse-angle stimuli were not significantly different from each other $(p>0.05)$. Note that the right-angle stimulus drawings were much more foreshortened than the others were, and this could explain the difficulty of matching up the correct drawing with this object. Many of the subjects confused the drawings of the right-angle and the obtuse-angle stimulus. If one were to adopt an incorrect vantage point, one that is excessively elevated, the right-angle stimulus could be drawn and seen as the drawing of the obtuse-angle object. 
A concern over the role of viewpoint and its relationship to linear perspective led to experiments 2 and 3 reported here. The CB subjects were no different than the others in this regard, since they performed similarly and there was a nonsignificant interaction between visual status and stimulus object.

The results of experiment 1 suggest that visual experience is not necessary for understanding some important aspects of linear perspective. This conclusion is supported by the similar performance that was found for the $\mathrm{CB}, \mathrm{LB}$, and sighted subjects. It was especially interesting that one $\mathrm{CB}$ subject mentioned, while feeling the choices for the right-angle object, that: “... so you sighted people don't see it as square”. Her comments reflected her realization that the felt square was not represented as a square, but rather as a considerably foreshortened quadrilateral. She also said: "You have hit on the problem that plagues blind people and drawing ... how to get a three-dimensional thing ... two-dimensional .... I can see this in my mind's eye, but I don't know how to get that on the board". Despite these protestations about task difficulty while drawing, this person had a score of 11 out of 12 correct on the multiple-choice task.

Most of the subjects were not skilled at producing perspective drawings, but these poor drawing skills were not reflected in performance on the multiple-choice task. Figure 3 shows some of the drawings produced by the visually impaired subjects. Note that while a number of the subjects were able to produce reasonable drawings of the obtuse stimuli, very few were able to do so for the acute-angle or the right-angle stimuli. A number of the drawings produced by the CB subjects were unskilled, but this is not surprising. It is extremely difficult to draw with correct perspective, both for sighted and visually impaired subjects. Sighted art students often have difficulty learning to draw in correct linear perspective. Perspective is a sophisticated intellectual achievement that appeared rather late in the historical development of art (Kubovy 1986; Panofsky 1925/1991) .

CB

(obtuse)
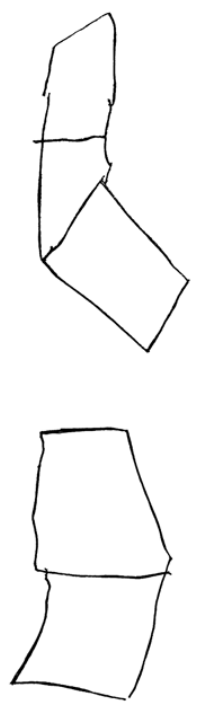

LB

(right angle)
CB

(obtuse)
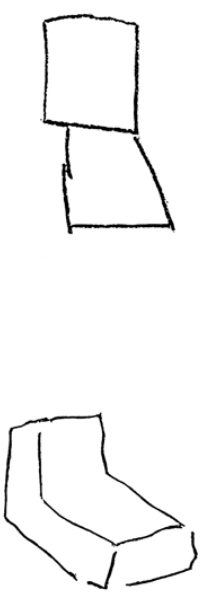

LB

(obtuse)
CB

(obtuse)
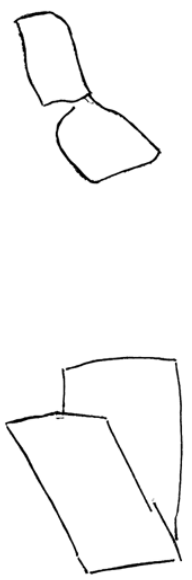

LV

(acute)

Figure 3. Raised-line drawings made by visually impaired subjects in experiment 1 . Note that $\mathrm{CB}$ refers to congenitally blind, LB refers to late blind, and LV refers to low vision. The drawings on the top by the CB are all of the obtuse-angle stimulus. 


\section{Experiment 2: The effects of picture viewpoint and viewpoint instructions}

The purpose of this experiment was to determine if tangible pictures vary in difficulty as a function of viewpoint. In experiment 2, blindfolded-sighted subjects were asked to feel geometric solids and select the appropriate raised-line drawing from a matching array consisting of four picture choices. The picture choices were all drawn from the vantage point of a frontal view, or a top view, or a foreshortened 3-D view. Some subjects were given prior verbal information about the viewpoint of the picture choices, while others were not given this information. It was expected that frontal views would be the easiest for the subjects, because of prior research (eg Heller et al 1995), and that prior information about the viewpoint of the pictures would aid performance. Moreover, it was expected that performance would be lower for pictures that expressed depth relations on a 2-D surface, such as the 3-D drawings. Also, lower performance was expected for top views, given the difficulty previously found with elevated views of a model house (Heller et al 1995). Most of the top views did not involve perspective cues. However, the other viewpoints used perspective, and could prove more difficult if perspective were a special problem for touch.

Front views might be easier if subjects typically think of objects that way. However, top views could be easier if they distinguish objects with minimal ambiguity.

\subsection{Method}

4.1.1 Participants. The subjects were seventy-two introductory psychology students recruited from the undergraduate subject pool at Eastern Illinois University. There were thirty-six males and thirty-six females, with sixty-seven self-identified as right-handed, three as left-handed, and two as ambidextrous. Subjects were randomly assigned to one of six independent groups involving the viewpoint of the drawing of the object (frontal view, 3-D view, and top view) and instruction about viewpoint (no instructions versus viewpoint instructions).

4.1.2 Stimuli. The five stimulus objects were an $8.9 \mathrm{~cm}$ cube, a pyramid with an $8.9 \mathrm{~cm}^{2}$ base, and a height of $6.3 \mathrm{~cm}$, an $8.9 \mathrm{~cm}$ high triangular prism, an $8.9 \mathrm{~cm}$ high hexagonal prism, and an $8.9 \mathrm{~cm}$ high rhombic prism (see figures $4 \mathrm{a}-4 \mathrm{~d}$ ). The four picture choices for each object were raised-line drawings, produced as in experiment 1 . The picture choices for each object included the correct choice, and three randomly chosen pictures of the other objects.

For the 3-D views (see figure $4 \mathrm{~b}$ ), the shapes were drawn from the vantage point of the viewer sitting $50 \mathrm{~cm}$ from the front edge of the object, and looking down at it from a height of $35 \mathrm{~cm}$ above the drawing surface. The frontal views were drawn as if the viewer's eyes were at the height of the top of the object, looking across its top. The frontal views were drawn without the use of converging lines at the top or bottom of the objects (see figure 4a). It was believed that touch might have trouble with perspective foreshortening (and converging lines), and so this type of drawing was selected on the assumption that it would make the task easier. The top views conveyed an elevated vantage point directly above the objects (figure 4c).

A $67 \mathrm{~cm} \times 72 \mathrm{~cm}$ mat board and foam board framework was designed to hold the objects and the picture choices (see figure 5). The sets of picture choices were mounted on $64 \mathrm{~cm} \times 20 \mathrm{~cm}$ mat board.

4.1.3 Design and procedure. A between-within design was used, with the betweensubjects variables being the viewpoint of the drawings of the objects (frontal view, top view, 3-D view) and viewpoint instructions (no instructions versus instructions); repeated measures were taken on trial block ( 3 blocks of trials). 
(a) Frontal view

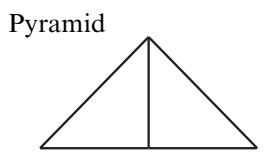

Triangular prism

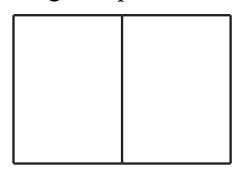

Hexagonal prism

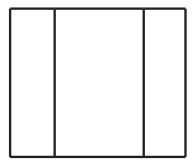

Rhombic prism
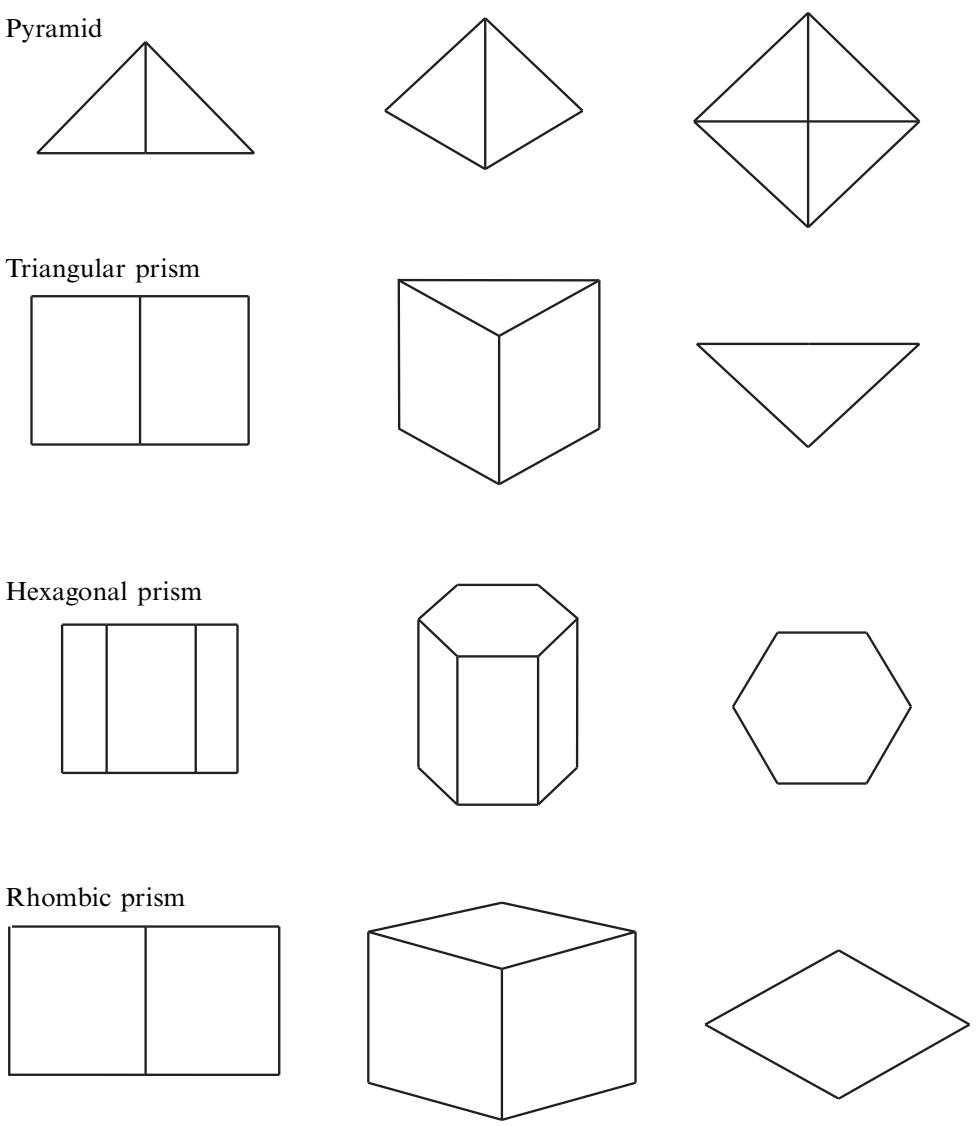

(d) Frontal-convergence
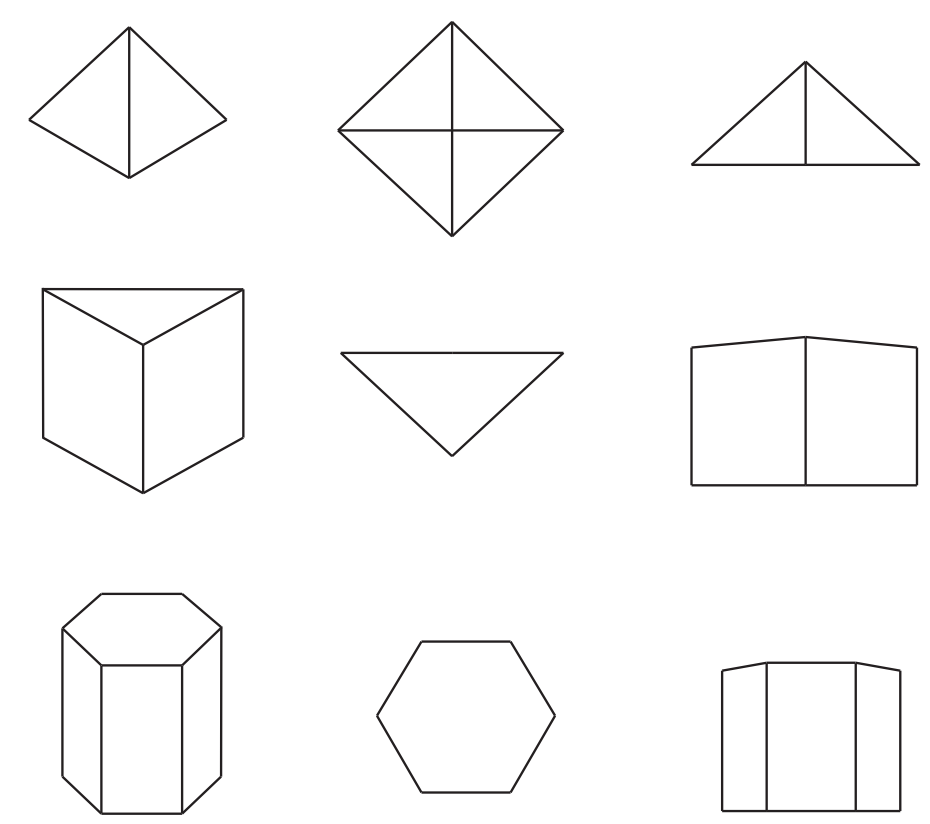

Cube
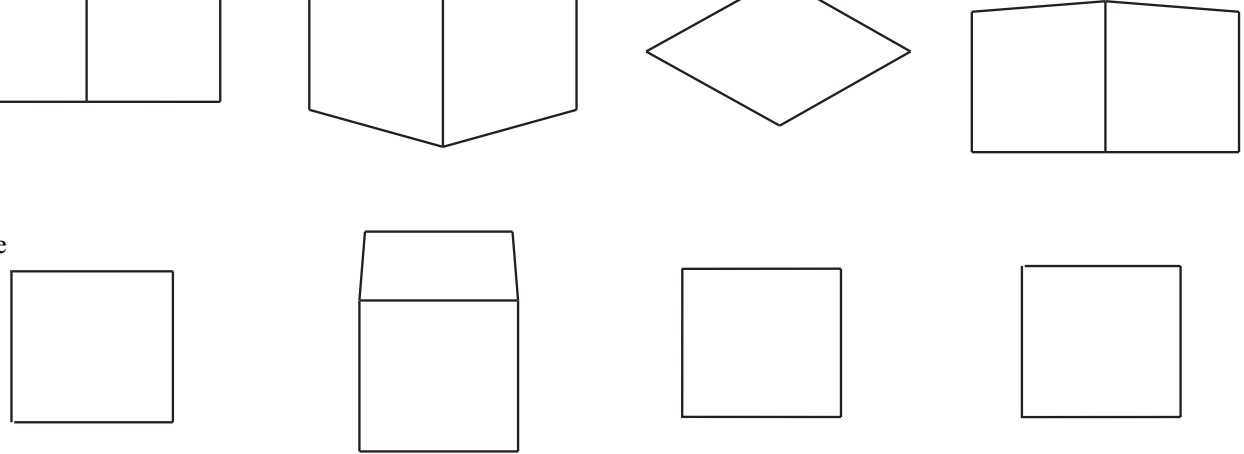

Figure 4. Drawings in experiments $2-6$ from a frontal view (a), three-dimensional view involving perspective (b), and top view (c). (d) Drawings in experiments 3 and 5 depicting the objects from a frontal viewpoint with converging lines for the top edges, where the bottoms of the objects were at eye-height.

Subjects were blindfolded throughout the experiment and were told that they would feel a wooden object, and then would feel four tangible pictures. They were to choose the correct picture from the choices, after feeling all of them. The subjects were told that they would be timed on the task, but that it was important to try for accuracy, in this and subsequent experiments. Participants were allowed to use one or both hands to feel the pictures, whatever their preference.

Viewpoint instructions were given after subjects were blindfolded. In addition to verbal instructions, each participant was also given a haptic demonstration, in the form of having the experimenter take his or her hand and place it on the object in an appropriate position for the viewpoint. For the frontal-viewpoint group, the subjects 


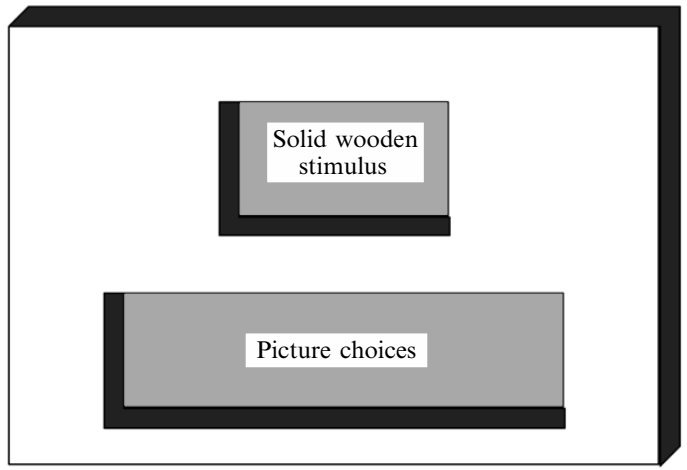

Figure 5. Framework for holding the objects and picture choices.

were told that the pictures were "frontal views" and to "imagine looking at the object with your eyes, from straight ahead, with the object at eye-height". For the top-viewpoint group, subjects were told that "the pictures are top, bird's-eye views". To illustrate the viewpoint, one of the subject's hands was placed on the top of a form that was not used in the experiment (a cylinder). The subjects given 3-D viewpoint instructions were told: "Try to imagine that you can see the object from where you are sitting". They were told that the views were foreshortened perspective viewpoints and they were given a demonstration of the angle of regard by taking one of their hands and moving it from eye-height to the demonstration object (cylinder). The subjects were also told that these 3-D viewpoints allowed them to see the top and front of the object at once.

It is not clear how the instructions involving 'looking from a viewpoint' may have affected the blind subjects, but they said that they understood this. The use of a haptic demonstration was designed to clarify the notion of angle of regard. Instructions about 'looking' from a vantage point were adopted, since some blind subjects have told $\mathrm{MH}$ that they tended to think of objects as 3-D, and not from a particular viewpoint. These same individuals claimed to know that sighted people imagine objects differently than blind people, since sighted people think of 'looking at an object' from a vantage point.

Note that the ease of selection of the correct view can be measured by the use of randomly selected distractors. Future experiments may require subjects to discriminate the correct choice from incorrect views of the same object, but that was not feasible given the present experimental design.

The subjects were timed with a stopwatch from the time that they first touched the solid wooden blocks until they indicated their match. Thus, response latency included the time to feel the wooden object, the time to feel all of the picture choices, and the time to indicate a selection.

\subsection{Results and discussion}

Table 3 summarizes the results of experiment 2 and shows mean number correct and mean time per trial. Subjects performed best on the top views. A 3 (viewpoint) $\times 2$ (instructions) $\times 3$ (trials) ANOVA performed on number correct showed a significant main effect of viewpoint $\left(F_{2,66}=63.12, p<0.0001\right)$, with superior performance on the top views. There was also a significant main effect of instructions $\left(F_{1,66}=5.59\right.$, $p=0.02$ ), and subjects performed better when given instructions about the viewpoint of the pictures. The main effect of trials was highly significant $\left(F_{2,132}=9.50\right.$, $p<0.001$ ), with an increase in performance over trials. A Newman-Keuls test on the means for the different viewpoints indicated that subjects performed significantly better on the top views $(M=95.0 \%$ correct $)$ than on the frontal views $(M=51.6 \%$ correct) or the $3-\mathrm{D}$ views $(M=56.6 \%$ correct; $p<0.05)$. The means for the $3-\mathrm{D}$ and frontal-viewpoint groups were not significantly different $(p>0.05)$. None of the interactions was significant (all $p \mathrm{~s}>0.10$ ). 
Table 3. Mean number correct and mean time per object for experiment 2 (with standard deviations in parentheses) for top, frontal, and 3-D drawings as a function of viewpoint instructions.

\begin{tabular}{lllll}
\hline Object & & & & Total \\
\cline { 2 - 6 } cube & pyramid & $\begin{array}{l}\text { hexagonal } \\
\text { prism }\end{array}$ & $\begin{array}{l}\text { triangular } \\
\text { prism }\end{array}$ & $\begin{array}{l}\text { rhombic } \\
\text { prism }\end{array}$ \\
\hline
\end{tabular}

Frontal view with viewpoint instructions

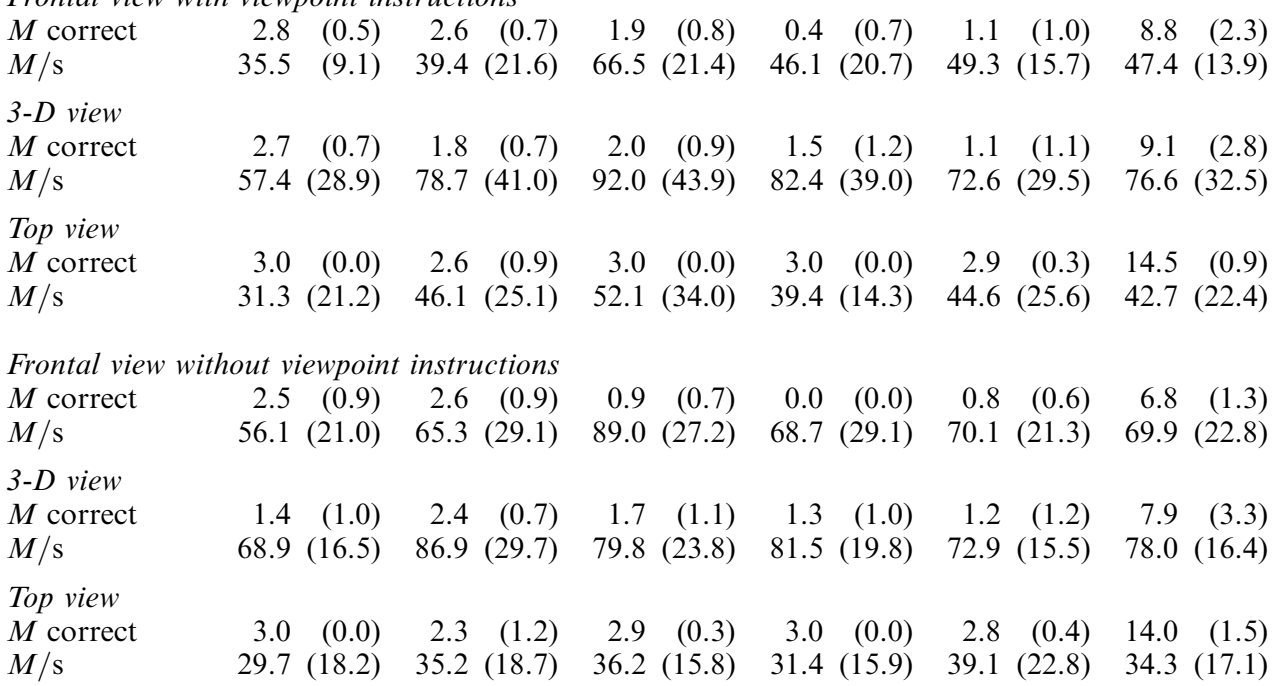

Note: Maximum score possible per object $=3$; total maximum score possible $=15$.

An additional analysis of variance was performed on number correct, but included object as a within-groups variable. A 3 (viewpoint) $\times 2$ (instructions) $\times 5$ (object) ANOVA performed on number correct showed a significant main effect of object $\left(F_{4,264}=30.52\right.$, $p<0.0001$ ) (see table 3). Mean numbers correct (out of three) for the cube, pyramid, hexagonal prism, rhombic prism, and triangular prism were 2.56, 2.38, 2.07, 1.64, and 1.53 , respectively.

The interaction between viewpoint and object was highly significant $\left(F_{8,264}=19.24\right.$, $p<0.0001)$. The simple effect of viewpoint was significant for all of the objects $(p<0.001)$ other than the pyramid $(p=0.11)$. Subjects tended to have special difficulty with top views of the pyramid.

A second ANOVA was performed on time scores, and included viewpoint, object, and trials as within-subject variables, but information about viewpoint was a betweengroups variable. The main effect of viewpoint of the pictures was highly significant $\left(F_{2,66}=19.11, p<0.0001\right)$. A Newman - Keuls test indicated that subjects were significantly faster on the top view $(M=38.52 \mathrm{~s})$ than the frontal views $(M=58.61 \mathrm{~s})$, and the 3 -D views $(M=77.31 \mathrm{~s})(p<0.05)$. Subjects were also significantly slower on the 3-D pictures than the frontal-viewpoint pictures. The main effect of object was also significant $\left(F_{4,264}=23.41, p<0.0001\right)$. A Newman-Keuls test on mean time scores showed that the cube $(M=46.49 \mathrm{~s})$ took significantly less time to identify than the other objects $(p<0.01)$.

The results of experiment 2 showed that the 3-D pictures were difficult, and this was as expected. Thus, the subjects had some difficulty with making the translation between the solid objects and the 3-D drawings expressed on a flat surface. However, the frontal views were also much harder than the top views, and this was surprising, given the results of prior research on model houses (Heller et al 1995). Subjects commented that 
they often had a difficult time imagining the appearance of the frontal viewpoint of the objects. Clearly, some classes of pictures pose special problems for touch, and not just because of the translation from a solid form to a flat drawing surface. It is hard to imagine some points of view, and this is dependent upon the nature of the stimuli and their configuration. The geometric forms that were used in experiment 2 were comprehensible in terms of their cross-sections, which were essentially top views. The increased difficulty for the frontal views may have derived from their use of perspective representation and lack of converging lines. Note that subjects could have difficulty distinguishing the frontal views of some of the objects because of similarity of proportions. Also, the 3-D views contain aspects of the top views within them, and this may help subjects identify them.

\section{Experiment 3: Frontal views with and without converging lines}

The purpose of this experiment was to examine the effect produced by the type of frontal viewpoint of the drawings used in experiment 2 , since performance was unexpectedly low for that viewpoint. The lack of converging lines was intended to make the task easier for subjects. It was thought that the use of converging lines in frontal views would increase task difficulty for touch. However, frontal-view drawings lacking converging lines (figure 4a) are typical of the views of very distant, rather than close objects, and this may have been a source of the difficulty for the subjects. Thus, experiment 3 was designed to compare drawings of the fronts of objects from viewpoints with or without converging lines in their upper contours.

\subsection{Method}

5.1.1 Participants. The subjects were twenty-four undergraduate students (twelve males, twelve females) recruited from the campus of Eastern Illinois University. Twenty-one of the subjects were right-handed, two were left-handed, and one was ambidextrous.

5.1.2 Stimuli and apparatus. The standard objects were the same as those used in experiment 2, except that one choice set was drawn with converging lines (see figure $4 \mathrm{~d}$ ). A second set of frontal views lacked converging lines (see figure 4a). The frontal views (without converging lines) of experiment 1 were produced by looking across the tops of the objects. The frontal views that included converging lines involved elevating the objects so that their bottoms were at eye-height. This yielded converging lines depicting the tops of some of the objects (see figure $4 \mathrm{~d}$ ).

5.1.3 Procedure. This experiment was a between-within design, with type of picture (frontal viewpoint or frontal viewpoint with converging lines) as a between-subjects variable, with repeated measures on trials. As in experiment 2, subjects were given the objects, and then asked to identify the correct raised-line drawing of the object from a set of picture choices. Half of the subjects had choice sets containing representations of the frontal viewpoints of the objects without converging lines, while the other group received perspective frontal views with converging lines. It is important to note that none of the subjects was given further instructions about the nature of the viewpoint of the pictures. Subjects were simply asked to find the correct picture, but were not told that the viewpoint of the pictures was frontal. In most respects, the procedure was identical to that of experiment 2.

\subsection{Results and discussion}

Performance was better for frontal views with converging lines. Mean numbers correct for the frontal views with converging lines and frontal viewpoints lacking them were 2.78 and 2.25 (out of 5), respectively. A 2 (picture type) $\times 3$ (trials) ANOVA performed on number correct revealed a significant main effect of picture type $\left(F_{1,22}=7.71\right.$, $p<0.02$ ). However, the main effect of trials was nonsignificant, as was the interaction between type of picture and trials (both $p \mathrm{~s}>0.10$ ). 
A 2 (type of picture) $\times 5$ (object) $\times 3$ (trial) ANOVA performed on time scores showed a significant main effect of type of picture $\left(F_{1,22}=4.38, p<0.05\right)$. Subjects took much longer to identify the simple frontal viewpoints $(M=69.85 \mathrm{~s})$ than the frontal views with converging lines $(M=51.31 \mathrm{~s})$. There was also a main effect of object $\left(F_{4,88}=15.05, p<0.0001\right)$. A Newman-Keuls test showed that subjects took significantly longer to identify the hexagonal prism $(M=76.78 \mathrm{~s})$ than the rhombic prism $(M=64.20 \mathrm{~s})$, and both of these objects took longer than the triangular prism, pyramid, and cube $(M \mathrm{~s}=56.45,54.50$, and $50.96 \mathrm{~s}$, respectively). The significant main effect of trials $\left(F_{2,44}=16.80, p<0.0001\right)$, derived from an increase in response speed over trials. None of the interactions was significant (all $p \mathrm{~s}>0.15$ ).

The results of experiment 3 show that the use of converging lines in drawings may actually improve recognition of haptic pictures in blindfolded-sighted subjects. Thus, converging lines in haptic drawings will not invariably increase task difficulty, as one might assume if linear perspective were a special problem for touch. Inclusion of some forms of perspective information may help blindfolded-sighted subjects as they try to generate mental images of the forms. Their past experience with drawing and perspective may cause them to generate visual images that include perspective cues and converging lines. Of course, these results may not hold for CB subjects, and that is the subject of a further experiment.

\section{Experiment 4: Touch restricted to the fronts, sides, and backs of the objects}

Observation of the subjects in experiment 2 indicated that many of them did not seem to spend much time feeling the fronts of the objects. It was therefore possible that they did poorly with frontal views because they spent insufficient time feeling the fronts of the objects. This led us to conduct an experiment in which we told some subjects to be sure to feel the fronts of the objects. However, this added instruction had no effect on performance. Consequently, we conducted a further experiment in which subjects were prevented from feeling the tops of the objects, and could only feel their fronts, sides, and backs. The tops of the objects were covered by a board that restricted subjects' exploration, and prevented them from grasping the tops. Presumably, subjects would be required to explore the fronts, sides, and backs of the objects to gain an appreciation of their forms. If failure to feel the fronts of the objects were a cause of the lower performance for the frontal views, then these subjects should have found the frontal views as easy as the top views. However, if the top views were most informative for the stimuli in the present study, then performance should still have been better for top views.

\subsection{Method}

6.1.1 Participants. The participants were thirty-six undergraduate students from Eastern Illinois University, recruited primarily through the undergraduate subject pool. There were eighteen male subjects and eighteen female subjects. Thirty-two were right-handed, and four were left-handed. Subjects were randomly assigned to the frontal-viewpoint group ( $n=12$, without converging lines, see figure 4a), 3-D viewpoint group $(n=12$, see figure $4 \mathrm{~b})$, and the top-viewpoint group ( $n=12$, see figure $4 \mathrm{c})$.

6.1.2 Stimuli and apparatus. A plywood apparatus was constructed to prevent subjects from feeling the tops of the objects (see figure 6). The apparatus was open in front and back, allowing the subject to reach inside to feel the objects. A hinged plywood board $(30 \mathrm{~cm} \times 27.3 \mathrm{~cm})$ was used to provide a movable horizontal cover for each object. Foam board was glued to the underside of the wooden cover to ensure a tight fit over the tops of the objects. This prevented subjects from feeling the objects from above. 


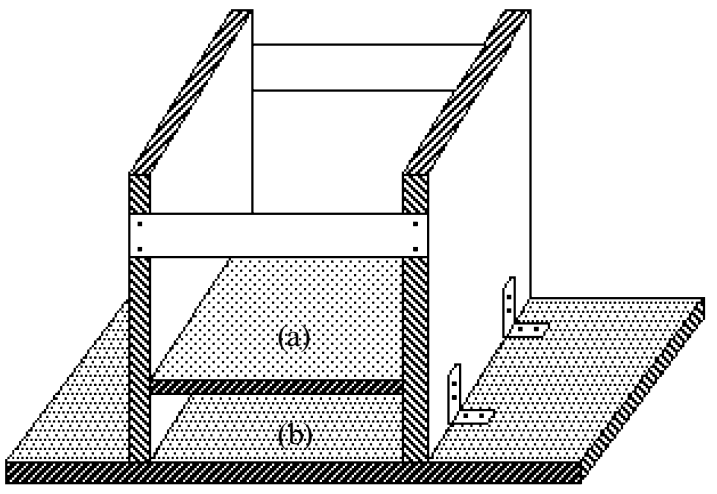

Figure 6. Apparatus used to prevent subjects from touching the tops of the objects in experiment 4: (a) hinged panel used to cover top of object; (b) plywood base of apparatus location of stimulus object.

6.1.3 Procedure. Subjects were told about the viewpoint represented in the pictures, and were asked to choose the correct picture. In most respects, the procedure was like that of experiment 2.

\subsection{Results and discussion}

Table 4 summarizes the results of experiment 4 . Consistent with the results of experiment 2, performance was better for the top-viewpoint pictures $(M=4.53$ correct out of 5) than for the frontal-viewpoint $(M=3.44)$ or the 3 -D views $(M=2.75)$. A 3 (viewpoint) $\times 3$ (trials) ANOVA performed on number correct, showed a significant main effect of viewpoint $\left(F_{2,33}=11.45, p<0.001\right)$. A Newman-Keuls test showed that the top viewpoint produced significantly more correct responses than the other viewpoints $(p<0.05)$; however, there was no significant difference between the 3-D viewpoint and frontal viewpoint $(p>0.05)$. The main effect of trial block was nonsignificant, and the interaction between viewpoint and trial block failed to reach significance (both $p$ s $>0.47)$.

The results of experiment 4 support those of experiment 2 and show that top views are easiest for blindfolded-sighted subjects. These results, showing lower performance for frontal viewpoints, cannot be explained in terms of subjects failing to feel the fronts of the objects, since the frontal pictures were still more difficult than top viewpoints in experiment 4. Subjects in experiment 4 were prevented from grasping the tops of the objects and forced to feel their fronts, sides, and backs.

Table 4. Mean number correct and mean time per object (with standard deviations in parentheses) for experiment 4 with subjects prevented from touching the tops of objects.

\begin{tabular}{lllll} 
Object & & & & \\
\hline cube & pyramid & $\begin{array}{l}\text { hexagonal } \\
\text { prism }\end{array}$ & $\begin{array}{l}\text { triangular } \\
\text { prism }\end{array}$ & $\begin{array}{l}\text { rhombic } \\
\text { prism }\end{array}$
\end{tabular}

Frontal view

$M$ correct

$\begin{array}{llllll}2.3 & (1.1) & 3.0 & (0.0) & 2.5 & (0.7)\end{array}$

$43.2(17.2) \quad 45.7(19.8) \quad 70.2(26.7)$

$0.9 \quad(1.0)$

$1.6 \quad(0.9)$

$10.3 \quad(2.3)$

$M / \mathrm{s}$

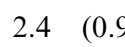

$\begin{array}{llll}1.8 \quad(1.0) & 1.8 \quad(1.3)\end{array}$

$65.1(28.8)$

$65.0(23.2)$

$57.8(20.1)$

3-D view

$M$ correct

$56.2(30.7) \quad 76.1 \quad(35.1)$

$67.5(20.9)$

$\begin{array}{llll}1.3 & (1.2) & 0.9 & (0.9)\end{array}$

$8.3 \quad(3.2)$

$M / \mathrm{s}$

$\begin{array}{rrrr}2.9 & (0.3) & 2.5 & (0.9) \\ 24.4 & (11.4) & 35.2 & (16.2)\end{array}$

$\begin{array}{llll}2.8 & (0.4) & 2.8 & (0.6)\end{array}$

$67.4(33.7)$

$69.9(30.9)$

Top view

$M$ correct

$M / \mathrm{s}$

24.4 (11.4) $35.2(16.2) \quad 36.9$ (15.7) 31.5 (13.9)

$\begin{array}{llll}2.6 & (0.8) & 13.6 & (2.7)\end{array}$

Note: Possible mean number correct per object $=3$; total possible number correct $=15$. 


\section{Experiment 5: Visual experience and viewpoint effects}

The purpose of experiment 5 was to examine the possible influence of visual experience on perception of tangible pictures.

\subsection{Method}

7.1.1 Participants. There were four groups of subjects (see table 1), including ten blindfolded-sighted subjects, ten LV subjects, ten CB subjects, and ten LB subjects (total $N=40$ ).

7.1.2 Stimuli and apparatus. The stimuli and equipment were identical to those in experiments 2 and 3. The subjects received random arrangements of the four viewpoints: frontal, frontal with converging lines, top views, and 3-D viewpoints. There were five objects for each viewpoint, with four picture choices for each. The sequences of viewpoints, objects, and choice pictures within each viewpoint were randomly generated.

7.1.3 Design and procedure. The experiment was a between-within design, with independent groups for the variable of visual status (blindfolded-sighted, CB, LB, LV) and repeated measures were taken on picture viewpoint (top, frontal, frontal with converging lines, 3-D). The subjects had 20 trials, with each trial consisting of an object and four picture choices. Picture viewpoint was blocked, but randomly presented. The sequence of pictures within each block was randomized.

The procedure was like that in experiment 2. Subjects were explicitly instructed about the viewpoints in the pictures that they felt. They were told to find the picture that showed the haptically explored object, and that the other pictures in each choice set showed the other objects.

Prior to the matching task, the subjects were exposed to the five objects, one at a time, and asked to draw them in any manner they wished. Of course, the sighted subjects were blindfolded.

Subsequently, the subjects were told about the viewpoint used to draw the picture choices, and this was demonstrated with the aid of a cylinder. For top views, the cylinder was placed on the table, and each subject's hand was placed on top, and moved vertically, up and down. Subjects were told: "These are top, bird's-eye views of the objects, as if you were looking directly down on these objects from above." For the 3-D drawings, the cylinder was placed on the tabletop, and each subject's hand was guided in a diagonal line from eye-level to the top, front edge of the object. The subjects were instructed: "These are three-dimensional perspective drawings. They were drawn from the point of view of someone looking down at an angle on the object. You can see both the front and the top of the wooden object from where you are." For the frontal viewpoint drawings, the cylinder was held at eye-height, with the top of the object approximately $50 \mathrm{~cm}$ horizontally distant from the subject's eyes. Each subject's hand was guided to the front of the object, and s/he was told: "The pictures were drawn from the point of view of someone looking at the front of each object. The views are straight-ahead, front views of the object." For the frontal viewpoint drawings with converging lines, the cylinder was held with the bottom edge at eye height at $50 \mathrm{~cm}$, and the subjects were told: "The pictures were drawn from the point of view of someone looking at the front, bottom edge of each object at eye height. The views are front views of the object, but there is some perspective, some distortion of the top front edge of the object." This was intended to help the CB subjects understand that these views differed from the other frontal views.

\subsection{Results and discussion}

A 4 (visual status) $\times 4$ (viewpoint) ANOVA was performed on number correct with the data collapsed across objects (see tables 5 and 6 ). The main effect of visual status was significant $\left(F_{3,36}=3.25, p<0.05\right)$, with better performance by the LV subjects. 
Table 5. Mean number correct and mean time for sighted and visually impaired subjects as a function of viewpoint in experiments 5 and 6 (with standard deviations in parentheses).

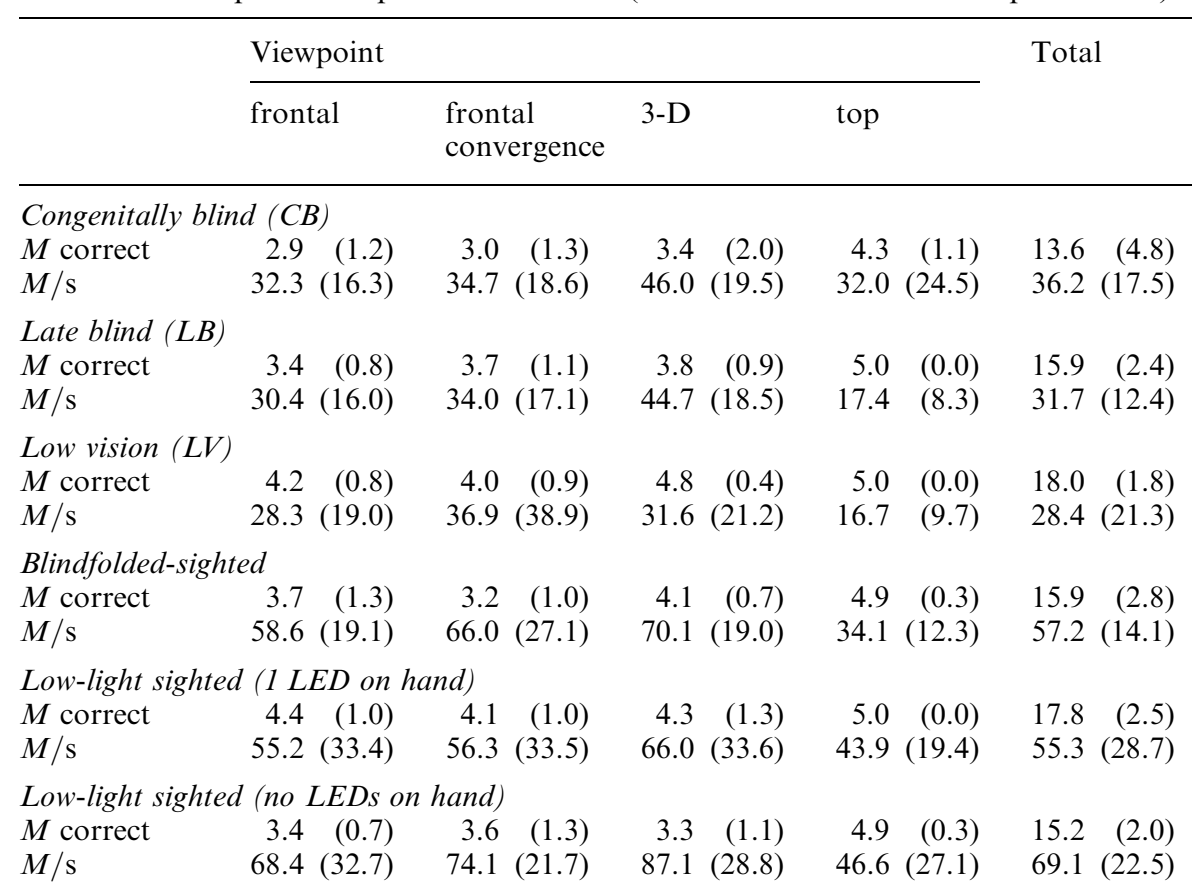

Note: Maximum number correct per viewpoint $=5$; maximum total number $\operatorname{correct}=20$. Vision was blurred in the low-light sighted groups with multiple layers of stained-glass; LED refers to light emitting diode.

A Newman-Keuls test showed that LV participants $(M=4.50$ correct $)$ had significantly higher mean scores than $\mathrm{CB}$ subjects $(M=3.40$ correct; $p<0.05)$, but all of the other comparisons were not significant (all $p \mathrm{~s}>0.05$ ). The main effect of viewpoint was highly significant $\left(F_{3,108}=30.44, p<0.0001\right)$, with higher performance on the top views. A Newman-Keuls test showed that the subjects correctly identified the top-view drawings significantly more often than all of the other viewpoints (all $p \mathrm{~s}<0.05)$. Moreover, performance on the 3-D view was significantly different from that on all other viewpoints. The means for the two types of frontal views were not significantly different from each other, but both were significantly lower than all of the other viewpoints. The interaction between visual status and viewpoint was not significant $\left(F_{9,108}=1.10, p=0.37\right)$.

Finally, a 4 (visual status) $\times 4$ (viewpoint) $\times 5$ (object) ANOVA was performed on time scores. There was a significant main effect of visual status $\left(F_{3,36}=6.05, p<0.01\right)$. Blindfolded-sighted subjects took the longest to identify the objects $(M=57.23 \mathrm{~s})$. A Newman-Keuls test showed that the CB, LB, and LV subjects performed the task in significantly less time than the sighted subjects, but were not significantly different from each other (see table 5). There was also a significant main effect of viewpoint $\left(F_{3,108}=22.07, p<0.0001\right)$. A Newman-Keuls test showed that subjects were significantly faster for top views $(M=25.07 \mathrm{~s})$ than the other viewpoints. Also, the 3-D viewpoint took significantly more time than the frontal-viewpoint pictures without converging lines.

There was a highly significant main effect of object $\left(F_{4,144}=13.41, p<0.0001\right)$. A Newman-Keuls test showed that subjects were significantly faster on the cube $(M=28.49 \mathrm{~s})$ than all of the other objects. 
Table 6. Mean number correct and mean time per object for the haptic viewpoint task (with standard deviations in parentheses).

\begin{tabular}{|c|c|c|c|c|c|c|}
\hline & \multicolumn{5}{|l|}{ Object } & \multirow[t]{2}{*}{ Total } \\
\hline & cube & pyramid & $\begin{array}{l}\text { hexagonal } \\
\text { prism }\end{array}$ & $\begin{array}{l}\text { triangular } \\
\text { prism }\end{array}$ & $\begin{array}{l}\text { rhombic } \\
\text { prism }\end{array}$ & \\
\hline \multicolumn{7}{|c|}{ Congenitally blind $(C B)$} \\
\hline$M$ correct & $3.4 \quad(1.1)$ & $3.5 \quad(0.5)$ & $2.7 \quad(1.6)$ & $2.0 \quad(1.2)$ & $2.0 \quad(1.2)$ & 13.6 \\
\hline$M / \mathrm{s}$ & $26.6(17.8)$ & $41.9(25.1)$ & $35.5(17.2)$ & $38.3(18.8)$ & $38.8(19.6)$ & $36.2(17.5)$ \\
\hline \multicolumn{7}{|c|}{ Late blind ( $L B)$} \\
\hline$M$ correct & $3.8 \quad(0.4)$ & $3.9 \quad(0.3)$ & $3.4 \quad(0.7)$ & $2.2(1.1)$ & $2.6 \quad(1.1)$ & $15.9 \quad(2.4)$ \\
\hline$M / \mathrm{s}$ & $27.6(18.1)$ & $27.1 \quad(8.3)$ & $37.2(18.3)$ & $31.8(15.1)$ & $34.6(16.0)$ & $31.7(12.4)$ \\
\hline \multicolumn{7}{|c|}{ Low vision $(L V)$} \\
\hline$M$ correct & $3.8 \quad(0.6)$ & $4.0 \quad(0.0)$ & $3.9 \quad(0.3)$ & $3.1 \quad(0.9)$ & $3.2(1.0)$ & 18.0 \\
\hline$M / \mathrm{s}$ & $17.6 \quad(9.9)$ & $23.4(13.5)$ & $31.4(29.8)$ & $34.9(31.2)$ & $34.6(26.6)$ & $28.4(21.3)$ \\
\hline \multicolumn{7}{|c|}{ Blindfolded-sighted } \\
\hline$M$ correct & $3.7 \quad(0.5)$ & $3.7 \quad(0.5)$ & $3.2 \quad(1.1)$ & $2.5 \quad(1.2)$ & $2.8 \quad(1.0)$ & $15.9 \quad(2.8)$ \\
\hline$M / \mathrm{s}$ & $42.2(14.8)$ & $46.4(16.0)$ & $69.0(20.3)$ & $66.3(19.3)$ & $62.2(17.6)$ & $57.2(14.1)$ \\
\hline \multicolumn{7}{|c|}{ Low-light sighted (1 LED on hand) } \\
\hline$M$ correct & $3.9 \quad(0.3)$ & $3.9 \quad(0.3)$ & $3.8 \quad(0.4)$ & $3.0 \quad(0.9)$ & $3.2(1.0)$ & $17.8 \quad(2.5)$ \\
\hline$M / \mathrm{s}$ & $45.0(30.3)$ & $53.2(28.7)$ & $61.9(38.1)$ & $59.4(31.0)$ & $57.3(24.7)$ & $55.3(28.7)$ \\
\hline \multicolumn{7}{|c|}{ Low-light sighted (no LEDs on hand) } \\
\hline$M$ correct & $3.7 \quad(0.5)$ & $3.4 \quad(0.7)$ & $3.2(0.9)$ & $3.7 \quad(0.7)$ & $2.5 \quad(0.7)$ & $15.2(2.0)$ \\
\hline$M / \mathrm{s}$ & $51.5(20.6)$ & $66.5(28.4)$ & $66.3(23.7)$ & $81.8(29.8)$ & $79.1(22.4)$ & $69.1(22.5)$ \\
\hline
\end{tabular}

Note: Maximum number correct per object $=4$; maximum total number correct $=20$. Vision was blurred in the low-light sighted groups with multiple layers of stained-glass; LED refers to light emitting diode.

These results show that 3-D views are not more difficult than all other viewpoints, and subjects undoubtedly benefited from prior information about the nature of the viewpoints. The lack of any interaction between visual status and viewpoint is consistent with theoretical points of view that suggest that pictures have considerable utility for blind people. The lower performance by the CB subjects, as compared with the LV subjects, was probably due to their restricted experience with tangible pictures, and not a lack of visual experience or visual imagery per se.

It should be noted that these results do not mean that all blind people will benefit equally from haptic pictures. A couple of the $\mathrm{CB}$ subjects did very poorly, and it is not known if their performance would improve with practice. However, some $\mathrm{CB}$ subjects did very well, and this included one subject who thought that pictures were not suitable for blind people. Prior to the experiment, he said that, while graphs and maps make sense to blind people (he had a tangible map on his wall), the idea of pictures for blind people was 'idiotic and stupid'. This negative bias did not keep him from performing very well on the viewpoint task.

The high performance of the LV subjects in experiments 1 and 5 was unexpected, and requires some comment. One additional explanation of the advantage of LV subjects should be mentioned. Some of the LV subjects had minimal object perception, and could coarsely localize very large objects in space. Moreover, they all had light perception. It is possible that the mere presence of light perception and very blurry vision could aid in many haptic-form perception tasks. Low lighting and blurry vision may help subjects in a number of haptic tasks, including Braille matching (Heller 1993), texture judgments (Heller 1989b), and identification of tangible 
pictures. $^{(1)}$ It is also possible that benefits may accrue if residual light perception allows crude spatial localization.

It should be noted that while the LV subjects in these experiments could not see the stimuli or raised-line drawings, they were not blindfolded. The sighted subjects were blindfolded, and we already have ample evidence that low lighting and blurry vision can aid haptics. The lack of vision could disorient sighted subjects. However, sighted individuals often report closing their eyes while using touch, even when blindfolded. They have said that this helped them concentrate, generate mental images, and ignore distractions. It is unlikely that blindfolding had a generally disruptive effect on haptic performance, since the sighted subjects did so well with the top views (4.9 correct out of 5).

\section{Experiment 6: Low lighting}

This experiment was designed to see if blindfolding lowered performance of the sighted subjects in haptic tasks involving pictures. Subjects were exposed to the procedures of experiment 5 , but with low lighting and blurred vision.

\subsection{Method}

8.1.1 Participants. There were twenty subjects, recruited from an undergraduate population.

8.1.2 Stimuli and apparatus. Room lights were turned off, and the sole source of light for the purposes of scoring derived from the use of two subminiature lamps (battery powered, light output $=0.81 \mathrm{lux}$ at $4 \mathrm{~cm} ; 1.5 \mathrm{~V}, 25 \mathrm{~mA}$ ). In addition, a Celestron astronomer's light-emitting diode (LED) light was used to aid in scoring, but was limited to the lowest light setting. These lights were used on a table top, but behind a large opaque black board. A red LED ( $1.5 \mathrm{~V}$ battery power, power dissipation of $60 \mathrm{~mW}$, luminous intensity of $6.3 \mathrm{mcd}$ ) was fastened on the top of each of the subject's right hands (at the midpoint, between the knuckles and wrist), and one was placed beneath each of the four choice pictures in the matching array. The subjects wore welder's goggles fitted with two layers of stained glass [see Heller (1993) for more details about the effects of stained glass]. The effect of stained glass and low lighting was to render the raised-line drawings and wooden objects invisible throughout the experiment. A second group experienced the same low-lighting procedures, but without the LED fastened on top of their right hands. These subjects were unable to see the location of their preferred hands as they explored the stimuli.

(1) Very low lighting helped sighted subjects when they attempted to identify tangible pictures. An experiment exposed sighted subjects $(N=40)$ to the fifteen tangible pictures used in earlier research (Heller et al 1996a). The raised-line pictures were drawn without ink, and were presented in a darkened room. In addition, subjects wore goggles fitted with two layers of stained glass [see Heller (1993) for a description of the effects of stained glass] and were dark-adapted. This prevented subjects from seeing the tangible drawings that they felt, and made it impossible for them to see the location of their hands in space. The procedures eliminated any visual shape perception. Some of the subjects were given prior categorical information about the pictures, that is they were told the superordinate picture category (furniture, parts of the body, kitchen utensils, vehicles, and fruit) and some were not given categorical information. Half of the subjects were tested with a blindfold, rather than under low lighting. The experiment was a between-groups design, with the factors being presence or absence of low lighting (low light, stained-glass goggles versus blindfold) and prior categorical information (present or absent). The effect of low lighting was significant $\left(F_{1,36}=3.99, p=0.05\right)$, as was the effect of categorical information $\left(F_{1,36}=62.52\right.$, $p<0.001)$. Subjects performed better under low lighting $(M=7.9$ correct overall), with $(M=9.9$ correct) or without $(M=5.8$ correct) prior categorical information. Performance was lower when subjects were blindfolded ( $M=6.6$ correct overall), in both the prior category information group ( $M=9.5$ correct) and the no information group $(M=3.7$ correct). Thus, it is very possible that the mere presence of light perception could aid performance in a variety of picture recognition tasks. 
8.1.3 Design and procedure. The independent groups of subjects were dark-adapted for 3 min prior to beginning the experiment. Room lighting was sufficiently low that nothing could be seen in the experimental room prior to this point. The effect of low lighting and blurred vision was to render the sighted subjects unable to see hand motion (without the LEDs) at the level of the table top, even at the conclusion of the experimental session. The subjects were unable to see the red LEDs at the beginning of the experiment, but could barely see them after the initial $3 \mathrm{~min}$ period of dark adaptation. In all other respects, the procedure was identical to that for the visually impaired subjects of experiment 5.

\subsection{Results and discussion}

The results were interesting, and the data for these groups of low-light, blurry-vision subjects were compared to the data for the blindfolded-sighted and LV subjects of experiment 5 (see tables 5 and 6). An ANOVA on number correct showed that performance was significantly altered as a function of the visual manipulation $\left(F_{3,36}=3.65\right.$, $p=0.02)$. Mean number correct for the LV subjects $(M=18$ correct $)$ and low-light, blurry vision $(M=17.8$ correct) sighted subjects with the LED on their hands was very similar; the two means were not significantly different $(F<1)$. Elimination of the LEDs on their hands lowered the mean scores of the blurry-vision, sighted subjects ( $M=15.2$ correct), and they performed at a slightly lower level than the blindfoldedsighted subjects $(M=15.9$ correct). The effect of picture viewpoint was highly significant $\left(F_{3,108}=20.7, p<0.001\right)$, but the interaction between visual group and viewpoint failed to reach significance $\left(F_{9,108}=1.7, p=0.093\right)$. A Newman-Keuls test on the mean number correct showed that top viewpoints were significantly easier than the other pictures $(p<0.01)$, and the frontal-viewpoint pictures with converging lines were significantly worse than the $3-\mathrm{D}$ picture means.

These results are important, and suggest that many studies may actually underestimate the haptic skills of blindfolded-sighted subjects (see Heller 1991, 2000). The present results suggest that the mere presence of minimal light perception can have a major impact on performance in haptic tasks, but only if the subjects can see the location of their hands in space. Thus, low lighting did not help the sighted subjects when they were unable to see hand location, in the group without LEDs on the top surface of their right hands. This also means that the results of the present experiments cannot be explained in terms of the interfering effects of blindfolding on the sighted subjects, since low lighting, per se, did not aid performance.

\section{General discussion}

The results of experiment 1 show that visual experience is not necessary for understanding some aspects of perspective. The CB subjects performed as well as the LB individuals with visual experience in experiment 1 on linear perspective and in experiment 5 on perspective and viewpoint effects. Taken together, these results suggest that raised-line drawings may be useful for the blind, a conclusion that is consistent with the extensive work of Kennedy $(1993,1997)$ in this area.

The success of the $\mathrm{CB}$ subjects in the perspective task of experiment 1 was noteworthy, and consistent with prior reports (Heller et al 1996b; Kennedy 1993). As in earlier research (Heller et al 1996b), CB people did not spontaneously generate accurate foreshortened drawings, but were able to make sense out of perspective depictions. These results are also consistent with earlier reports of the ability of CB individuals to adopt an appropriate vantage point when interpreting perspective pictures (Heller and Kennedy 1990; Heller et al 1995). Note that there was a nonsignificant interaction between visual status and stimulus object in experiment 1 . This meant that the $\mathrm{CB}$ subjects were no less able than the other subjects in adopting the vantage point assumed 
by the perspective drawings. The subjects in all of the groups had more difficulty with the foreshortened depictions of the right-angle stimulus in experiment 1. It is suggested that the untutored drawing and graphics skills of blind people are likely to show improvement with practice and instruction. However, this is an empirical question, worthy of further investigation.

\section{Viewpoint and picture difficulty}

The results of experiments 2, 3, and 5 suggest that pictures vary considerably in the ease with which people can interpret them, and relate them to solid geometric forms. All subjects found that the top views were much easier to identify than the other pictures, which all depicted linear perspective. It is inappropriate to assume that because perspective is perceived in vision, it cannot be perceived in the absence of visual experience. The results of experiment 5 show that visual experience is not necessary for identifying perspective drawings. Moreover, the 3-D views were no more problematic than frontal views, and were sometimes easier. Thus, perspective representations are accessible to many blind people, but perhaps only with some prior instruction about the nature of the drawings. The use of converging lines did not increase task difficulty in experiments 3 and 5, and helped in experiment 3. This suggests that subjects in experiment 1 probably made use of directional cues and convergence when making their judgments. It was interesting that one CB participant spontaneously drew a good $3-\mathrm{D}$ view of the cube. His depiction was similar to that of the 3-D cube in figure 4.

One reviewer cogently pointed out that the top views and the frontal views in parallel projection do not contain useful information about 3-D aspects of form. The top views provide good information only about a horizontal planar cross-section of the objects. This explains some of the difficulty that subjects had with the top views of the pyramid. These pictures using parallel projection of the front and top of an object may not give much useful information about slant in depth. Thus, the 3-D perspective views give us the most useful information about depth information in geometric solids, but were not the easiest sorts of depictions given the majority of forms used in these experiments. Future research will examine a wider range of objects, and further clarify the roles of polar projection and parallel projection in tangible pictures.

The top views were easiest by far. They allowed subjects to discriminate the forms of the objects, many of which differed in proportion when drawn as frontal views. Thus, the rhombic prism and the triangular prism generated frontal views that were similar, but the top views were easy to discriminate.

These conclusions on visual experience and perspective depictions require some qualification, since there were large individual differences between the various $\mathrm{CB}$ individuals. Some did very well with the perspective tasks in experiments 1 and 5, but a couple of the CB participants did extremely poorly. While some CB subjects can make sense of simple perspective drawings, the notion of perspective is not simple, and is not limited to a drawing of a single object in space (see Panofsky 1925/1991). Complex perspective representations involve drawings of multiple objects within a 3-D space. In true perspective, the picture is transformed, so that "... we are meant to believe we are looking into this window into a space" (Panofsky 1925/1991, page 27). Note that the invention of mathematical perspective is a relatively recent event in the history of human art (eg Kubovy 1986; Panofsky 1925/1991; Tyler 2000), and many sighted individuals require considerable instruction before they are able to produce complex drawings of scenes in correct perspective. The comprehension of complex scenes by the blind will be the topic of future research, but goes well beyond the scope of this study. 


\section{Blurry vision aids touch}

The high levels of performance by the LV subjects also suggest the value of tangible pictures. Instruction in the rules for pictorial representation will probably prove helpful for visually impaired people. The majority of people with visual impairment are likely to benefit from tangible pictures. Moreover, anyone can benefit from tangible pictures, even if simply for aesthetic purposes. Tangible pictures might act as windows into one's imagination, much as nonrepresentational abstract paintings do for sighted people.

The results of control experiments simulating low vision suggest that minimal light perception, per se, is not sufficient to explain excellent performance in touch. The sighted subjects who excelled did so only when they were able to see the location of their right hands in space. Low lighting and blurry vision allowed these subjects to localize the objects that they were feeling, rather coarsely in space. This was also helped by the use of the LEDs beneath the picture locations. However, picture localization information alone was not sufficient to raise the performance of the sighted to that of the LV subjects. Higher performance was prompted when the subjects were able to see the location of their right hands and the locations of the pictures in space. It is not clear if the benefit derived solely from the ability to localize their hands in space, or if higher performance levels also required the presence of the LEDs beneath the tangible pictures. The presence of the LEDs beneath the pictures did more than merely localize them in space. The combined effect of LEDs beneath the pictures and on top of the subjects' right hands was to allow them to obtain visual information about the orientation of their forearms in space. Thus, they occluded the LEDs marking off picture location (with their wrists) while feeling a picture above an LED, and could also see the location of their right hands. It is conceivable that the important manipulation involved just placing an LED on top of the hand to provide vision of hand location, but additional research will be required to separate the effects of these variables. In any event, it is certain that sight of one's hand position in space is helpful for optimal performance in this task. Conceivably, adding LEDs or lights to the hands of LV subjects may aid picture perception, but this is the subject of future research.

The advantage of the LV subjects requires some additional comment. It is impossible to rule out the possibility that they could use vision for object recognition. However, this is an unlikely explanation of the data, given observation of their behavior and the evidence from blurred vision and low lighting in sighted subjects. Absolute certainty that vision is unavailable can only be assured by blindfolding. Moreover, one can present this claim about all research using blind subjects with minimal light perception, but who are not blindfolded. Researchers rarely report using blindfolds in studies of blind people. However, it was thought that blindfolding LV subjects would induce distress, and would also disrupt normal functioning.

While all of the LV subjects in this study had light perception, many of them did not have the ability to see hand motion. Some of them could see hand motion, and the present results suggest that this may be an especially important variable in subject selection. Future research will need to look very closely at how researchers operationally define samples of blind and visually impaired subjects.

Acknowledgments. Preparation of this report and the research were supported by NIH RO1 EY12040. We are grateful to Shavonda Green for help with constructing the stimuli in experiment 1, and to Angie Allen, Denise Hunley, Millissa Milbern, and Daniela Silva for assistance with data collection. Faith Heller provided helpful comments on an earlier version of this manuscript. 


\section{References}

Arditi A, Holtzman J D, Kosslyn S M, 1988 "Mental imagery and sensory experience in congenital blindness" Neuropsychologia $261-12$

Farah M J, 2000 The Cognitive Neuroscience of Vision (Oxford: Blackwell)

Hatwell Y, 1984 Piagetian Reasoning and the Blind Ed. B Stephens, translated by P Verdet (New York: American Foundation for the Blind)

Heller M A, 1989a "Picture and pattern perception in the sighted and blind: The advantage of the late blind" Perception $18379-389$

Heller M A, 1989b "Texture perception in sighted and blind observers" Perception \& Psychophysics 45 49- 54

Heller M A, 1991 "Haptic perception in blind people", in The Psychology of Touch Eds M A Heller, W Schiff (Hillsdale, NJ: Lawrence Erlbaum Associates) pp 239-261

Heller M A, 1993 "Influence of visual guidance on Braille recognition: Low lighting also helps touch" Perception \& Psychophysics 54 675-681

Heller M A (Ed.), 2000 Touch, Representation and Blindness Debates in Psychology Series (Oxford: Oxford University Press)

Heller M A, Brabyn J, 1997 "Ergonomic considerations in blind and low vision rehabilitation", in Perspectives in Rehabilitation Ergonomics Ed.S Kumar (London: Taylor and Francis) pp $69-94$

Heller M A, Brackett D D, Scroggs E, Allen A C, Green S, 2001 "Haptic perception of the horizontal by blind and low-vision individuals" Perception $30601-610$

Heller M A, Calcaterra J A, Burson L L, Tyler L A, 1996a "Tactual picture identification by blind and sighted people: Effects of providing categorical information" Perception \& Psychophysics $\mathbf{5 8} 310-323$

Heller M A, Calcaterra J A, Tyler L A, Burson L L, 1996b "Production and interpretation of perspective drawings by blind and sighted people" Perception 25321 - 334

Heller M A, Kennedy J M, 1990 "Perspective taking, pictures and the blind" Perception \& Psychophysics $\mathbf{4 8} 459-466$

Heller M A, Kennedy J M, Joyner T D, 1995 "Production and interpretation of pictures of houses by blind people" Perception $241049-1058$

Holmes E, Hughes B, Jansson G, 1998 "Haptic perception of texture gradients" Perception 27 $993-1008$

Kennedy J M, 1993 Drawing and the Blind (New Haven, CT: Yale University Press)

Kennedy J M, 1997 "How the blind draw" Scientific American 276(1) 76-81

Kennedy J M, 2000 "Recognizing outline pictures via touch: alignment theory", in Touch, Representation and Blindness Ed. M A Heller, Debates in Psychology Series (Oxford: Oxford University Press) pp 67-98

Kubovy M, 1986 The Psychology of Perspective and Renaissance Art (New York: Cambridge University Press)

Lederman S J, Klatzky R L, Chataway C, Summers C, 1990 "Visual mediation and the haptic recognition of two-dimensional pictures of common objects" Perception \& Psychophysics 47 $54-64$

Merry R V, Merry F K, 1933 "The tactual recognition of embossed pictures by blind children" Journal of Applied Psychology $17148-163$

Millar S, 1991 "A reversed lag in the recognition and production of tactual drawings. Theoretical implications for haptic coding", in The Psychology of Touch Eds M A Heller, W Schiff (Hillsdale, NJ: Lawrence Erlbaum Associates) pp $301-325$

Millar S, 1994 Understanding and Representing Space: Theory and Evidence from Studies with Blind and Sighted Children (Oxford: Oxford University Press)

Millar S, 2000 "Modality and mind: convergent active processing in interrelated networks as a model of development and perception by touch", in Touch, Representation and Blindness Ed. M A Heller (Oxford: Oxford University Press) pp 99-141

Newell F N, Ernst M O, Tjan B S, Bulthoff H H, 2001 "Viewpoint dependence in visual and haptic object recognition" Psychological Science 12 37-42

Panofsky E, 1925/1991 Perspective as Symbolic Form (1991, New York: Zone) (originally published in 1925)

Revesz G, 1950 The Psychology and Art of the Blind (London: Longmans Green)

Rock I, DiVita J, 1987 “A case of view-centered object perception' Cognitive Psychology 19 280-293

Tyler C W, 2000 "Perspective as a geometric tool that launched the Renaissance" Proceedings of the Society for Photo-Optical Instrumentation Engineers $3959492-497$ 
